BMJ Open Diabetes Research \& Care

\title{
Physicians' real-world experience with IDegLira: results of a European survey
}

\author{
Russell Drummond, ${ }^{1}$ Ankita Baru, ${ }^{2}$ Marcelina Dutkiewicz, ${ }^{3}$ Amaury Basse, ${ }^{3}$ \\ Bengt-Olov Tengmark ${ }^{4}$
}

To cite: Drummond $R$, Baru A, Dutkiewicz M, et al. Physicians' real-world experience with IDegLira: results of a European survey. BMJ Open Diab Res Care 2018;6:e000531. doi:10.1136/ bmjdrc-2018-000531

- Additional material is published online only. To view please visit the journal online (http://dx.doi.org/10.1136/ bmjdrc-2018-000531).

Received 5 March 2018 Accepted 15 May 2018

Check for updates

${ }^{1}$ Department of Diabetes, Endocrinology and Clinical Pharmacology, Glasgow Royal Infirmary, Glasgow, UK ${ }^{2}$ IOVIA, Rotkreuz, Switzerland ${ }^{3}$ Novo Nordisk A/S, Søborg, Denmark

${ }^{4}$ Citydiabetes, Stockholm, Sweden

Correspondence to Dr Russell Drummond; russell.drummond@glasgow. ac.uk

\section{ABSTRACT}

Objective This study aimed to build on the current clinical findings and investigate physicians' experiences and level of satisfaction in using insulin degludec/liraglutide (IDegLira) to treat patients with type 2 diabetes (T2D). Research design and methods This multicountry, European online survey included respondents from primary $(n=132)$ and secondary $(n=103)$ care and examined physicians' use, confidence and satisfaction with IDegLira. To standardize responses, 24 of 28 questions pertained to an 'average patient' with T2D who has no major comorbidities, aged 35-70 years, with average cognitive ability/normal mental status and body mass index $\geq 25 \mathrm{~kg} / \mathrm{m}^{2}$.

Results The majority (70\%) of respondents prescribe IDegLira in the same visit they first mention it, with uncontrolled glycated hemoglobin ( $\mathrm{HbA} 1 \mathrm{c})(44 \%)$ and weight gain $(22 \%)$ being the most common reasons. On average, physicians reported that patients weighed 95 $\mathrm{kg}$ and the $\mathrm{HbA} 1 \mathrm{c}$ level was $9.0 \%$ at initiation. Physicians also reported the average $\mathrm{HbA} 1 \mathrm{c}$ target set was $7.1 \%$; $76 \%$ of patients achieved their target. On average, patients achieved their HbA1c target in $<6$ months, and the average dose of IDegLira in patients in glycemic control was 28 dose steps. Respondents were more satisfied with IDegLira than basal-bolus therapy across all parameters assessed, including reaching $\mathrm{HbA1c}$ targets (59\%), number of injections (77\%) and avoiding weight gain (84\%). Correspondingly, $77 \%$ of physicians reported that IDegLira had more potential to improve patient motivation compared with basal-bolus to reach target blood glucose levels.

Conclusions Real-world experience of IDegLira is consistent with previous trials/studies, with no major differences between primary and secondary care. Importantly, the majority of respondents were more/much more satisfied with IDegLira than with basal-bolus therapy.

\section{INTRODUCTION}

Insulin degludec/liraglutide (IDegLira) is a once-daily, fixed-ratio combination of long-acting basal insulin degludec with the glucagon-like peptide-1 receptor agonist (GLP-1RA) liraglutide for the treatment of type 2 diabetes (T2D). ${ }^{1-4}$ Basal insulin/ GLP-1RA combination therapies might help tackle clinical inertia by virtue of their pragmatic titration algorithm, low rates of hypoglycemia, and benefit of either weight loss or

\section{Significance of this study}

What is already known about this subject?

- The majority of people with type 2 diabetes are still not achieving good glycemic control despite the availability of a wide range of effective diabetic therapies, and treatment intensification is often inappropriately delayed by the patient and/or physician as a result of concerns about detrimental side effects, such as hypoglycemia and weigth gain, and burdensome regimens.

- The clinical utility of insulindegludec/liraglutide (IDegLira) has been evaluated in the Dual Action of Liraglutide and Insulin Degludec in Type 2 Diabetes (DUAL) phase III clinical trial program and observational studies. Results show that once-daily IDegLira generally results in improved glycated hemoglobin and a low risk of weight gain and hypoglycemia, suggesting it has potential to tackle clinical inertia.

What are the new findings?

- This survey is the first to gather real-world data on physicians' experience in using IDegLira, and the results show that real-world experience of IDegLira is in alignment with trial findings.

- Real-world experience of IDegLira is also consistent between primary and secondary care, with respondents being satisfied with IDegLira, more so than with basal-bolus therapy, the current 'gold standard'.

How might these results change the focus of research or clinical practice?

- These results show IDegLira is an attractive intensification strategy suitable for initiation by primary care physicians as well as specialists.

- These findings suggest that IDegLira could help tackle clinical inertia at the physician level.

weight neutrality. ${ }^{5}$ Clinical inertia remains prevalent, particularly with regard to intensification with, or of, basal insulin. ${ }^{6-8}$ Even the most recent estimates of clinical inertia are based on time to initiation with more traditional and complex intensification strategies such as basal insulin, basal-bolus regimens, and premixed insulin. ${ }^{6-8}$ All of these regimens can involve multiple daily injections, a high risk of hypoglycemia, weight gain and-in the case of premixed insulins-resuspension 
of the protaminated insulin crystals. ${ }^{9-12}$ Hence, in the absence of comparative data on time to initiation with basal insulin/GLP-1RA combination therapies, it is valuable and timely to evaluate physicians' experience of prescribing and titrating IDegLira, now that it has been approved in Europe (September 2014) and in the USA (November 2016). ${ }^{12}$ In the USA, IDegLira is indicated as an adjunct to diet and exercise to improve glycemic control in adults with T2D inadequately controlled on basal insulin $(<50 \mathrm{U})$ or liraglutide $(\leq 1.8 \mathrm{mg}){ }^{1} \mathrm{In}$ Europe, IDegLira is indicated for the treatment of adults with T2D to improve glycemic control in combination with oral antidiabetic drugs (OADs) when these alone or combined with a GLP-1RA or basal insulin do not provide adequate glycemic control. ${ }^{2}$

The phrase III clinical trial program (Dual Action of Liraglutide and Insulin Degludec in Type 2 Diabetes; DUAL) investigated the safety and efficacy of IDegLira in insulin-naive patients and also in patients uncontrolled on either basal insulin or GLP-1RAs. Findings from the DUAL I-VI trials demonstrate that IDegLira treatment results in significantly greater glycated hemoglobin (HbA1c) reductions compared with either component alone and mitigates important primary adverse effects associated with insulin therapy (weight gain and hypoglycemia) and GLP-1RA therapy (gastrointestinal side effects) ${ }^{13-18}$ DUAL VII compared IDegLira with basalbolus therapy, which is still widely regarded as the gold standard in basal insulin intensification. In this treatto-target, non-inferiority trial, 506 patients with T2D uncontrolled on metformin and insulin glargine U100 (IGlar) were randomized to receive either IDegLira or basal-bolus therapy (IGlar+insulin aspart up to four times a day). Compared with basal-bolus therapy, IDegLira resulted in non-inferior HbAlc reductions, lower total daily insulin dose at the end of the trial, weight loss (vs weight gain with basal-bolus therapy) and a lower risk of hypoglycemia. ${ }^{19}$

Real-world IDegLira data are also accumulating and have demonstrated that treatment results in significant reductions in $\mathrm{HbAlc}$ with no weight gain and a low risk of hypoglycemia in patients from a variety of initial regimens. These include insulin-naïve patients and those receiving basal insulin and/or GLP-1RA or multiple daily injections of insulin, all with or without OADs. ${ }^{20-22}$

This survey aimed to build on the findings from clinical trials and clinical practice to date and investigate physicians' experiences and satisfaction with IDegLira therapy.

\section{RESEARCH DESIGN AND METHODS}

The study included respondents from four countries in which IDegLira was available at least 15 months before the study: UK $(n=100)$, Sweden $(n=61)$, Switzerland $(n=50)$ and Austria $(n=24)$. At the time of the study, IDegLira therapy was recommended for restricted use within the UK National Health Service, and reimbursed in Sweden (for patients with T2D uncontrolled on basal insulin) and Switzerland (for patients with T2D uncontrolled on metformin or basal insulin and with body mass index $\left.(\mathrm{BMI})>28 \mathrm{~kg} / \mathrm{m}^{2}\right)$; in Austria, individual reimbursement was required.

The questionnaire was developed by Novo Nordisk (online supplementary material), and the survey was conducted by QuintilesIMS (Durham, North Carolina, USA). Responses were collected between November 2016 and January 2017. Respondents included physicians from primary care (general practitioners, family practitioners, internal medicine physicians) and secondary care (diabetologists and endocrinologists) and were recruited-independently of Novo Nordisk-from QuintilesIMS' panel of physicians. One (Austria, Switzerland) or two (UK, Sweden) cognitive debriefings were held with the respondents via telephone or online teleconference to confirm the questionnaire had been translated correctly and the respondents understood the questions. Once this was confirmed, the respondents were invited to complete the 15 min online survey and were remunerated for their participation (equivalent range $€ 1-€ 2.5$ per min).

Any respondents treating fewer than two patients with IDegLira were excluded from the survey. In order to standardize responses, the majority $(24 / 28)$ of questions pertained to an 'average IDegLira patient' defined as a patient with T2D who has no major comorbidities, aged between 35 and 70 years, with average cognitive ability/ normal mental status and BMI $\geq 25 \mathrm{~kg} / \mathrm{m}^{2}$. The results described here pertain to this definition of an average IDegLira patient, unless otherwise stated.

\section{RESULTS}

\section{Respondent profile}

In total, 235 physicians completed the questionnaire, of whom 132 (56\%) were from primary care and 103 (44\%) were secondary care specialists. The respondents' profile is summarized in table 1 . Responses indicate that, after basal insulin, 35\% of respondents' patients are typically switched to basal-bolus regimens, $24 \%$ to basal insulin with a GLP-1RA, $17 \%$ to premixed insulin and $12 \%$ to IDegLira. This was largely similar between primary care physicians (PCPs) and specialists.

\section{Average patient profile at time of IDegLira initiation}

The respondents indicated their patients had, on average, an HbA1c level of 9\% (range 6.5\%-15.0\%) and weighed $95 \mathrm{~kg}$ (range 64-135 kg) at the time of IDegLira initiation. Answers from the PCPs (average HbAlc $9.1 \%$, range $7.0 \%-15.0 \%$; average weight $95 \mathrm{~kg}$, range $66-135 \mathrm{~kg}$ ) were consistent with those from the specialists (average $\mathrm{HbAlc} 8.9 \%$, range $6.5 \%-15.0 \%$; average weight $96 \mathrm{~kg}$, range $64-135 \mathrm{~kg}$ ).

In terms of regimens prior to IDegLira initiation, the most common physicians' responses are summarized in figure 1 . Please note answers were not mutually exclusive. Overall, the most common responses were basal insulin 


\begin{tabular}{|c|c|c|c|}
\hline Respondents & $\begin{array}{l}\text { Total } \\
(n=235)\end{array}$ & $\begin{array}{l}\text { Primary } \\
\text { care } \\
(n=132)\end{array}$ & $\begin{array}{l}\text { Secondary } \\
\text { care } \\
(n=103)\end{array}$ \\
\hline Number of respondents & 235 & 132 & 103 \\
\hline Austria & 24 & 12 & 12 \\
\hline Switzerland & 50 & 35 & 15 \\
\hline Sweden & 61 & 31 & 30 \\
\hline UK & 100 & 54 & 46 \\
\hline \multicolumn{4}{|c|}{ Percentage of physicians responding that they treat } \\
\hline $\begin{array}{l}\text { Less than } 50 \text { patients } \\
\text { with } \mathrm{T} 2 \mathrm{D} / \mathrm{month}\end{array}$ & 24 & 27 & 20 \\
\hline $\begin{array}{l}\text { 50-99 patients with } \\
\text { T2D/month }\end{array}$ & 46 & 55 & 33 \\
\hline $\begin{array}{l}100-149 \text { patients with } \\
\text { T2D/month }\end{array}$ & 19 & 13 & 26 \\
\hline $\begin{array}{l}\text { 150-199 patients with } \\
\text { T2D/month }\end{array}$ & 6 & 2 & 10 \\
\hline $\begin{array}{l}\text { More than } 200 \text { patients } \\
\text { with T2D/month }\end{array}$ & 6 & 3 & 11 \\
\hline \multicolumn{4}{|c|}{ Percentage of physicians responding that they treat } \\
\hline $\begin{array}{l}\text { 2-5 patients with } \\
\text { IDegLira/month }\end{array}$ & 47 & 59 & 31 \\
\hline $\begin{array}{l}\text { 6-10 patients with } \\
\text { IDegLira/month }\end{array}$ & 27 & 27 & 28 \\
\hline $\begin{array}{l}\text { 11-15 patients with } \\
\text { IDegLira/month }\end{array}$ & 9 & 6 & 14 \\
\hline $\begin{array}{l}\text { More than } 15 \text { patients } \\
\text { with IDegLira/month }\end{array}$ & 17 & 8 & 27 \\
\hline
\end{tabular}

Across all countries, a total of 4261 physicians and 195 nurses were invited to complete the survey, and a total of 235 physicians and 0 nurse completed the survey.

NB: The percentage of respondents is reported to the nearest whole number so the sum may not total to $100 \%$ exactly.

IDegLira, insulin degludec/liraglutide; T2D, type 2 diabetes.

$( \pm$ OADs $)$ and GLP-1RA therapy, either alone or in combination. The above-mentioned responses were broadly consistent across PCPs and specialists. However, when grouping responses according to regimen complexity, $26 \%$ of the PCPs answered that an average patient would be on either basal insulin or GLP-1RA therapy only compared with $12 \%$ of specialists (figure $1 \mathrm{~B}$ ).

Over half $(53 \%)$ of specialists and $40 \%$ of PCPs considered the free combination to be the most relevant alternative to IDegLira, followed by uptitration of basal insulin (39\% overall) or intensification to basal-bolus therapy (30\% overall).

The average responses indicate that the most common reasons for IDegLira initiation in respondents' total IDegLira-treated population were uncontrolled blood glucose $(44 \%)$ and patient problems with gaining weight (22\%). The next most common reasons included patients finding their previous treatment too complex (14\%), followed by problems with hypoglycemia (12\%), and patients expressing prior problems with nausea or other gastrointestinal side effects $(6 \%)$. This trend was consistent across answers from specialists and PCPs (online supplementary figure $1 \mathrm{~A}$ ).

\section{Physician confidence and satisfaction with IDegLira}

Responses showed that $85 \%$ of specialists compared with $55 \%$ of PCPs were either 'confident' or 'very confident' in uptitrating IDegLira (online supplementary figure 2A), while $52 \%$ of specialists and $33 \%$ of PCPs were 'confident' or 'very confident' of their patients' ability to self-titrate (online supplementary figure 2B). The majority of PCPs and specialists were more satisfied with IDegLira compared with basal-bolus regimens, across all proposed parameters, with greatest proportions being for avoiding weight gain, number of injections and incidence of hypoglycemia (figure 2). Specialists reported a greater level of satisfaction with IDegLira than PCPs across the majority of parameters (figure 2).

The majority of respondents were also 'more satisfied' or 'much more satisfied' with IDegLira than basal-bolus treatment in terms of simplicity of therapy, timing of dosing, patient satisfaction, patient adherence, and ease of training patients. Correspondingly, $77 \%$ of physicians responded that IDegLira had more potential to improve patient motivation to reach target blood glucose levels (figure 3A). The majority of respondents cited increased concern about hypoglycemia and weight gain with basalbolus therapy compared with IDegLira (figure 3B), but increased concern about nausea and other gastrointestinal side effects with IDegLira compared with basalbolus therapy.

\section{Physicians' experience with IDegLira use and effectiveness}

The majority of physicians prescribe IDegLira during the same visit in which they introduce it to their patients ( $70 \%$ overall, $65 \%$ of PCPs, $76 \%$ of specialists). For the remaining physicians, two further visits over 3 months were required, on average, before they prescribe IDegLira (table 2). The mean HbAlc targets set for IDegLira-treated patients by PCPs and specialists were $7.2 \%$ and $7.0 \%$, respectively (table 2 ).

Three-quarters of physicians reported that their average patient was able to achieve their $\mathrm{HbAlc}$ targets with IDegLira, and that this involved, on average, three visits and two telephone calls over a period of less than 6 months (table 2). The mean daily IDegLira dose for an average patient in glycemic control was reportedly higher for specialists than for PCPs (33 and 24 dose steps, respectively; 28 dose steps overall). Furthermore, a greater number of specialists $(n=11,11 \%)$ compared with PCPs $(n=4,3 \%)$ prescribed the maximum dose of 50 dose steps of IDegLira (table 2). The range of responses is shown in online supplementary figure 3 .

Physicians instructed their patients to take a greater number of self-measured blood glucose (SMBG) tests before they reached their target with IDegLira compared with after they reached their target, with 57\% 


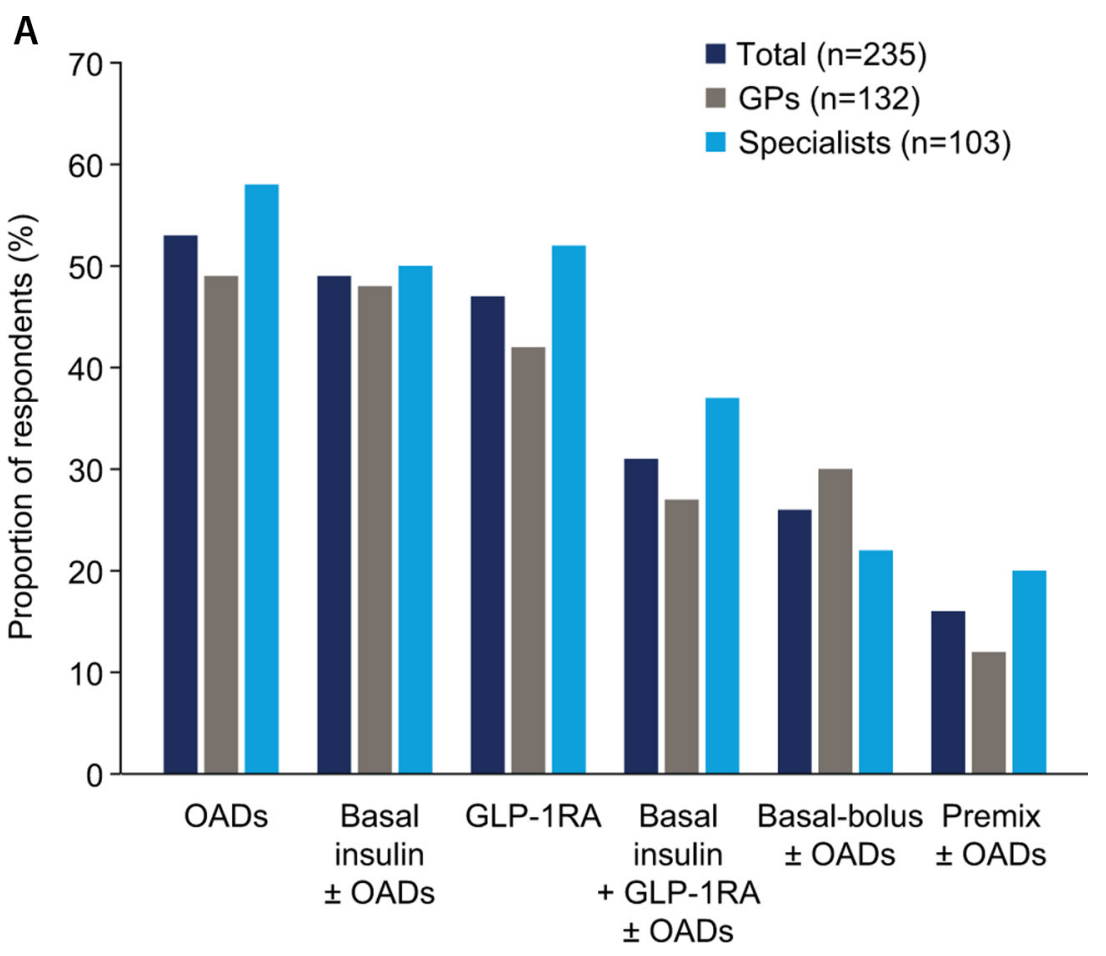

B Multiple choice response to the question 'What treatment(s) was the patient receiving prior to treatment with IDegLira?'

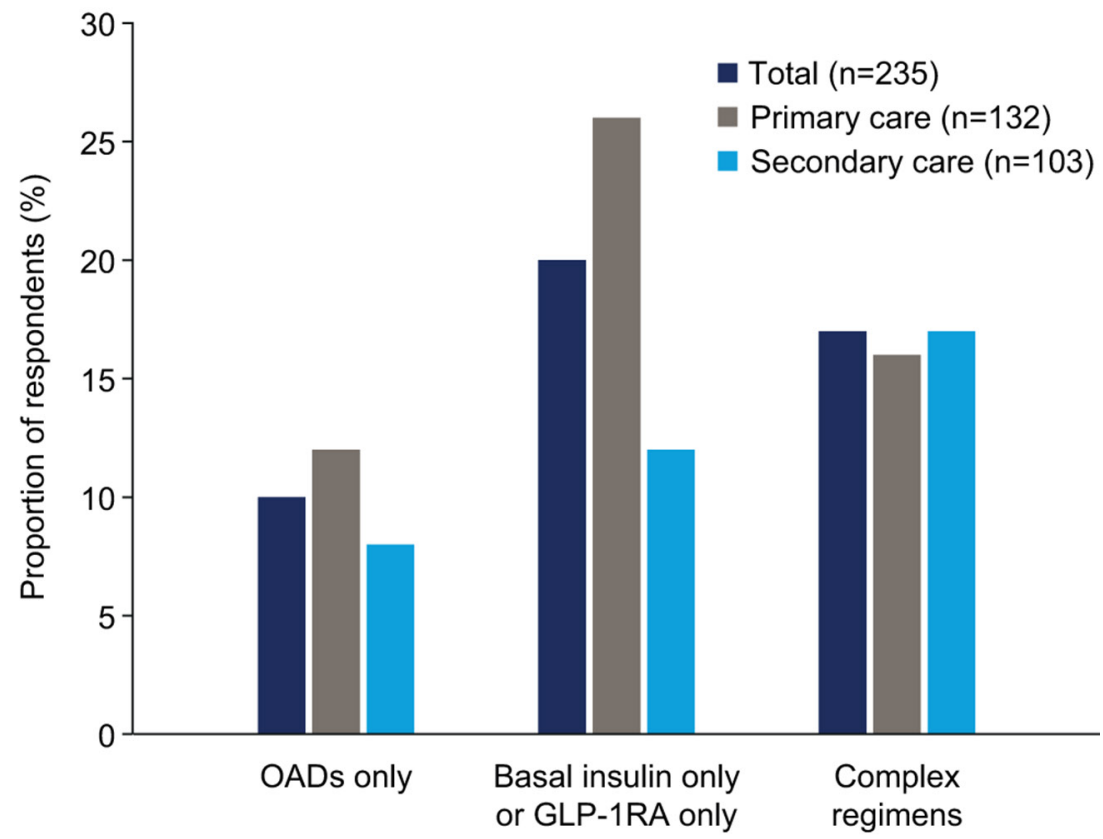

Category of response to the question 'What treatment(s) was the patient receiving prior to treatment with IDegLira?'

Figure 1 Average patient profile in terms of (A) previous therapy drug class and (B) complexity of previous regimen. Respondents could choose one or several of the answers presented in (A). However, only responses cited by $>15 \%$ of respondents are presented here; hence, the percentage of respondents citing combinations of these answers is not shown. 'OADs only' refers to respondents who selected OADs only; 'basal insulin only' or 'GLP-1RA only' refers to respondents who selected basal insulin with or without OADs or GLP-1RA, or a combination of the two; 'complex regimens' refers to respondents who selected 'basal+bolus \pm OADs', 'basal+GLP-1RA \pm OADs', 'premix \pm OADs' and any combination of these three. GLP-1RA, glucagon-like peptide-1 receptor agonist; GPs, general practitioners; IDegLira, insulin degludec/liraglutide combination; OADs, oral antidiabetic drugs. 


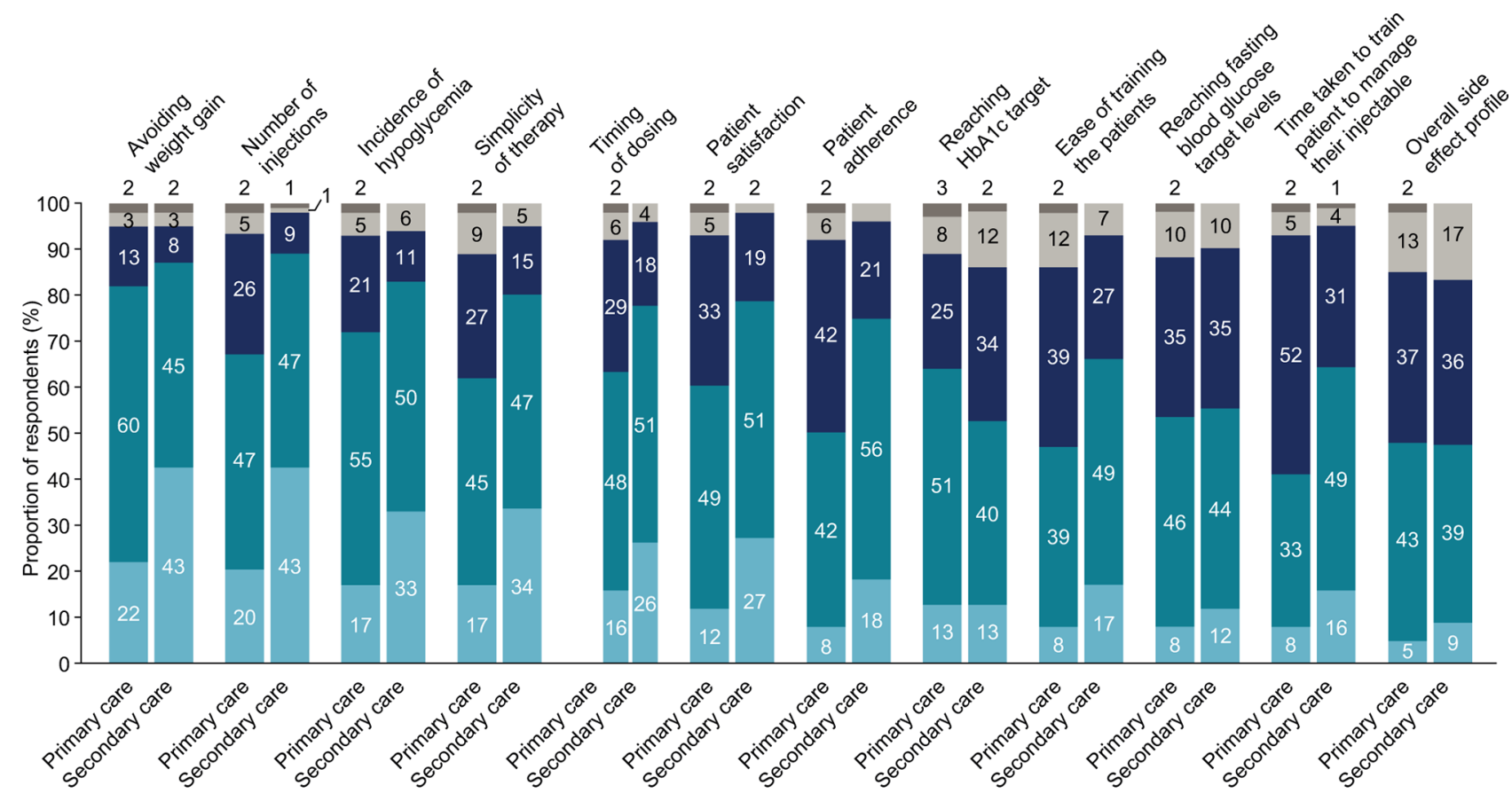

Response to the question 'Please compare your SATISFACTION of treating patients with IDegLira compared to basal-bolus based on each of the following?'

Much more satisfied with IDegLira $\quad$ More satisfied with IDegLira \# Equally satisfied with both
$\square$ More satisfied with basal/bolus $\quad$ Much more satisfied with basal/bolus

Figure 2 Satisfaction of respondents with IDegLira compared with basal-bolus. HbA1c, glycated hemoglobin; IDegLira, insulin degludec/liraglutide.

of respondents citing multiple tests/day before target achievement compared with $20 \%$ after target achievement. In addition, more specialists versus PCPs instructed their patients to take SMBG tests four ( $11 \%$ vs $9 \%)$, three (21\% vs $18 \%$ ) and two (37\% vs $22 \%$ ) times a day. In cases where patients were unable to achieve the target HbA1c, more than half of physicians $(61 \%)$ responded that these patients were instructed to measure blood glucose multiple times a day.

Physicians responded that the main reason for any of their patients not achieving HbAlc targets with IDegLira was that the patient had recently initiated treatment $(35 \%)$, followed by lack of adherence $(15 \%)$ and nausea and other gastrointestinal side effects (10\%). Overall, $15 \%$ of physicians responded that their average patient discontinues IDegLira (table 2), of whom 90\% responded that their patient does so within 6 months $(45 \%$ within 3 months and $45 \%$ between 4 and 6 months; consistent across PCPs and specialists). When considering all their patients on IDegLira, 31\% of physicians stated none of their patients discontinued IDegLira, and of the $69 \%$ of physicians who responded that some of their patients discontinued, the average percentage of patients cited to discontinue was $15 \%$. The most common reasons cited for IDegLira discontinuation were lack of effect on HbAlc control (23\%), followed by nausea or other gastrointestinal side effects $(20 \%)$ and level of patient copay $(17 \%)$ (online supplementary figure 1B). Overall, the main patient concerns recalled by respondents were fear of weight gain, with $28 \%$ of physicians responding that it was mentioned 'regularly' or 'always' by their patients, followed by adhering to the regimen (25\%) and difficulty in calculating the correct dose (23\%) (online supplementary figure 4).

\section{CONCLUSIONS}

The findings from this European survey of primary and secondary care physicians demonstrate that their experience of real-world IDegLira use is in alignment with clinical findings from the DUAL clinical trial program and/or observational studies-with responses indicating that the average patients reach their HbAlc target in a timely manner with IDegLira. No major differences were observed between responses from primary and secondary care. Importantly, these results indicate that physicians are satisfied with IDegLira-more so than with basalbolus regimens-in terms of efficacy, safety and simplicity of use.

The DUAL VII trial demonstrated that, compared with basal-bolus therapy, IDegLira treatment resulted in similar HbA1c reductions, weight loss versus weight gain, lower rates of hypoglycemia and improved patient-reported outcomes, particularly in domains relating to treatment burden. ${ }^{19}$ In addition, a short-term cost-effectiveness analysis of DUAL VII demonstrated that IDegLira is a cost-effective treatment for patients failing to achieve glycemic control on basal insulin in the USA. ${ }^{23}$ Based on this, one might expect physicians to favor IDegLira over basal-bolus for their patients, and the results from this 
A

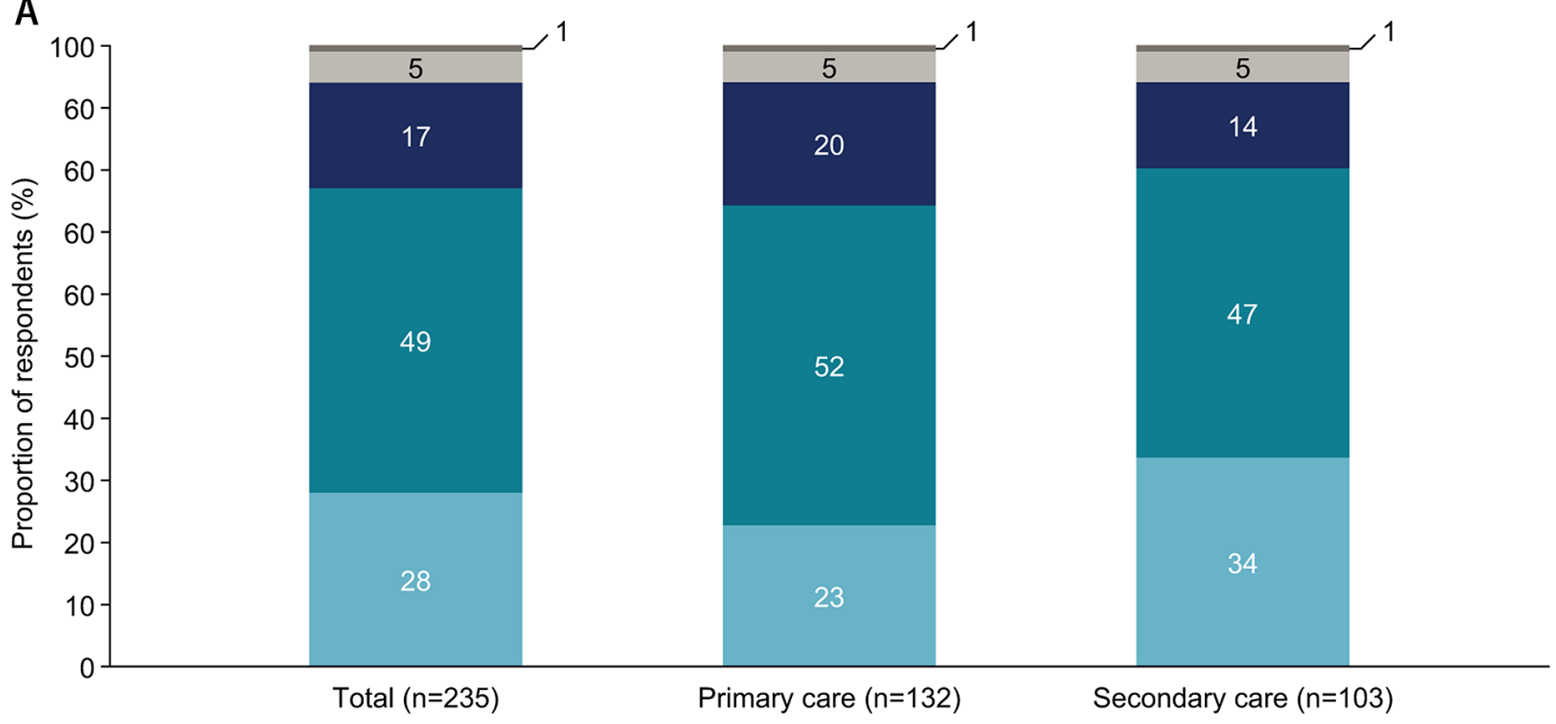

Response to the question 'Based on your experience, how motivated are patients to reach their target blood glucose levels with IDegLira compared to basal-bolus?'

- IDegLira has much more potential to improve motivation

- IDegLira is somewhat the same as basal-bolus

Basal-bolus has much more potential to improve motivation
- IDegLira has a little more potential to improve motivation

- Basal-bolus has a little more potential to improve motivation
B Concern of patients
having hypoglycaemia

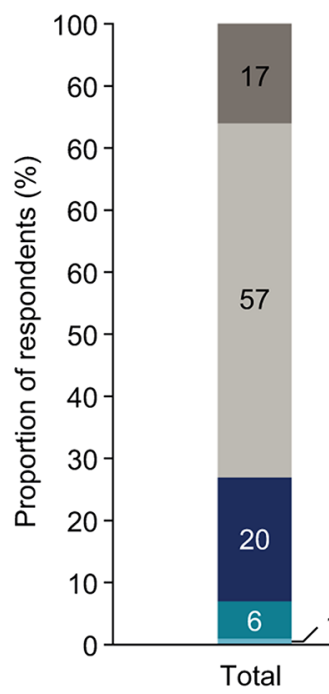

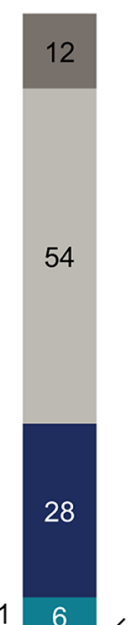

Primary Secondary
care care
Concern of patients
gaining weight
Concern of patients struggling with nausea and other $\mathrm{Gl}$ effects

Response to the question 'Based on your experience, what are your concerns for treating patients with basal-bolus compared with IDegLira?'
Much more concerned with IDegLira
- More concerned with IDegLira
Equally concerned with both
More concerned with basal-bolus
Much more concerned with basal-bolus

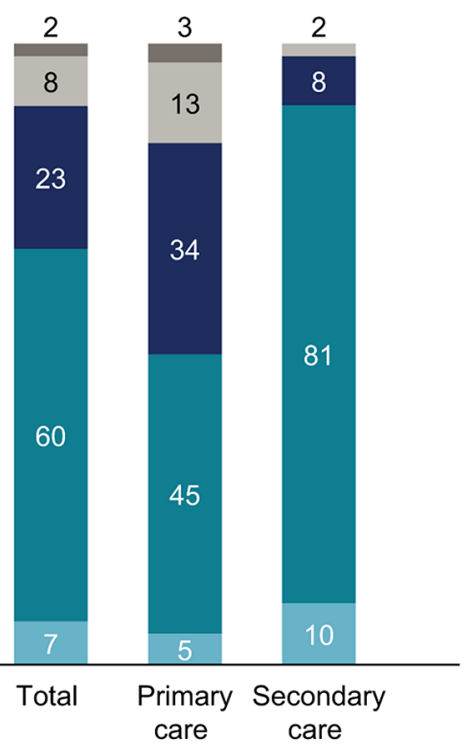

Figure 3 Respondents' perceptions on (A) the potential of IDegLira compared with basal-bolus therapy to improve patient motivation to reach their target blood glucose levels; and (B) concerns with IDegLira compared with basal-bolus therapy. GI, gastrointestinal; IDegLira, insulin degludec/liraglutide.

European survey support this, with physicians reporting they are more satisfied with IDegLira compared with basal-bolus over all proposed parameters. The strongest areas are avoiding weight gain, number of injections, incidence of therapy and timing of dosing, all of which are also commonly cited patient concerns. ${ }^{24}$
Physicians responded that treatment regimens used prior to IDegLira initiation included OADs alone or in combination with either basal insulin, GLP-1RAs, a free combination of basal insulin and GLP-1RAs, basal-bolus or premixed insulin, which is in agreement with findings from the European Xultophy ${ }^{\circledR}$ Treatment Retrospective 
Total

$(\mathrm{n}=235)$

Percentage of physicians who responded that their average IDegLira patient achieved their target $\mathrm{HbA} 1 \mathrm{c}$

Target $\mathrm{HbA} 1 \mathrm{c}$ level, \%

Average time taken and resources required between IDegLira initiation and achievement of $\mathrm{HbA} 1 \mathrm{c}$ targets

Average number of visits required

Average number of telephone calls required

Average number of months

Average dose of IDegLira when the average patient was in glycemic control, dose steps

Number of respondents prescribing a maximum dose of 50 dose steps 15 to an average IDegLira patient in glycemic control

Percentage of physicians who responded that their average patient discontinued IDegLira

Average percentage of respondents' total IDegLira-treated patient population who discontinued IDegLira (range)
76

7.1

$\begin{array}{ll}3.4 & 3.7 \\ 2.3 & 2.2 \\ 5.8 & 5.9 \\ 28 & 24\end{array}$

3.7

3.0

2.2

2.5

5.7

33

$15 \quad 4$

4

11

15

17

13

$15(1-80) \quad 16(1-80)$

$14(1-50)$
Secondary care ( $n=103)$

\section{4}

7.0

HbA1c, glycated hemoglobin; IDegLira, insulin degludec/liraglutide.

Audit (EXTRA) study. ${ }^{22}$ The majority of physicians responded that IDegLira was prescribed at the same visit as it was introduced to an average patient of theirs, suggesting that the majority of patients were not reluctant to initiate IDegLira. This is reassuring considering that delays in treatment intensification are often observed in clinical practice, even with insulin-experienced patients. ${ }^{8}$ Indeed, studies report delays of several years; the median time to intensification from becoming above target was over 6.0 years for basal insulin initiation ${ }^{7}$ and 3.7 years for insulin intensification ${ }^{8}$ in the UK. Importantly, three-quarters of physicians responded that an average IDegLira patient was able to achieve their HbAlc target over an average period of less than 6 months. It would be interesting to repeat this survey in the future, given that respondents also said that the reason for one-third of their patients not achieving HbAlc targets was because they had only recently initiated IDegLira. Together, these results suggest that the proportion of patients achieving HbAlc targets might be relatively high compared with other findings from observational studies in T2D. ${ }^{25-27}$ For example, a retrospective cohort study of real-world insulin initiation in patients with T2D found that $1110(73 \%)$ and $703(46 \%)$ of patients had HbAlc $\geq 7.5$ and $\geq 8.5 \%$, respectively, after 6 months. ${ }^{25}$ It is important to note that the results of this real-world survey seem to broadly resemble those of the DUAL clinical trial program, in which a high percentage of patients achieved $\mathrm{HbAlc}$ targets $(<7.0 \%)$ within 6 months. ${ }^{13}{ }^{14-19}$ It is important to note that respondents did not give the proportion of their patients achieving HbAlc $<7 \%$ or their individual HbA1c targets. Nonetheless, that the mean HbA1c target $(7.1 \%)$ and time to target (6 months) cited by respondents are similar to the recommendations for most patients in the latest diabetes management guidelines ${ }^{1028}$ is reassuring.

The average dose of patients in glycemic control (28 dose steps) was also in alignment with that previously reported in observational studies (30 dose steps after 6-month follow-up in EXTRA). ${ }^{22}$ These doses are lower than those reported from DUAL clinical trials, in which participants are closely monitored and titrated twice weekly, suggesting that greater glycemic control might be possible with more stringent titration. ${ }^{13-19}$ However, it is important to note that the majority of respondents still observe achievement of HbAlc targets within 6 months despite the relatively lower dose of IDegLira used compared with clinical trials.

Timely achievement of HbAlc targets would suggest that physicians are confident in titrating IDegLira and the responses certainly support this. Only $5 \%$ of PCPs and $4 \%$ of specialists were 'not very' or 'not at all' confident in uptitrating IDegLira. Specialists were more confident than PCPs in uptitrating IDegLira, as would be expected given their specialist expertise and greater experience. ${ }^{29}$ Physicians were not as confident in their patients' ability to titrate. The large proportion of 'neutral' responses across specialties might reflect a lack of physician knowledge, that is, titration might be nurse-led, or a neutral response in comparison with their confidence in the ability of a trained healthcare professional. Alternatively, it might be because of the relatively novelty of basal insulin/GLP-1RA fixedratio combination therapy or it might signal concerns with complexity of IDegLira regimen for a patient. 'Adhering to regimen' and 'difficulty in calculating correct dose/understanding dose steps' were among the most common patient concerns with IDegLira cited by respondents (all cited by $\leq 25 \%$ of respondents). However, again it is not known 
whether these concerns are specific to IDegLira, or more general concerns of any injectable therapy. For example, these concerns are widely cited by physicians as barriers to initiation of injectable therapy, ${ }^{60}$ and addition of a further $\mathrm{OAD}$ is often preferred to initiation of injectable therapy, ${ }^{31}$ despite the benefits of initiating insulin and/or GLP-1RA therapy. ${ }^{5} 1032$ Nonetheless, the satisfaction scores for IDegLira when compared with basal-bolus regimens in parameters such as 'ease of training patients', 'time taken to train patient to manage their injectable therapies', 'patient adherence' and 'simplicity of therapy' suggest that neutral response does not reflect a negative appraisal of IDegLira user-friendliness. Indeed, only $14 \%$ of respondents overall were not confident in their patients' ability to self-titrate.

According to physicians' responses, approximately $15 \%$ of patients discontinue IDegLira, with the majority who do doing so within 6 months. Insulin discontinuation rates vary according to the length of follow-up and study population, but they are often considerably greater than $15 \%,{ }^{33-36}$ with one observational study $(\mathrm{n}=7932)$ demonstrating $27 \%$ of patients with T2D discontinue insulin within the first 120 days. ${ }^{33}$ The reasons for discontinuation are not captured in these studies, but in EXTRA the main reasons included lack of effect on blood glucose control, nausea or other gastrointestinal side effects, and level of patient copay. Low discontinuation rates were also observed with IDegLira in the DUAL clinical trial program and in the EXTRA study.

\section{Limitations}

One limitation inherent to this survey is that the data are not based on clinical records, but rather on the physicians' experience, and can therefore be subject to recall bias. It would therefore be helpful to compare IDegLira-associated clinical values recalled by respondents with a different therapy, but only questions pertaining to respondent' satisfaction included a comparator therapy. Stratification based on prior treatment might help interpret responses to questions such as those relating to concerns that might differ between patient subgroups. It is unknown how representative the selection of physicians surveyed is. It is important to note that the timely achievement of HbA1c targets recalled by respondents is in alignment with clinical findings from the DUAL clinical trial program $^{13} 1416-19$ and EXTRA study. Several questions pertained to a definition of an 'average patient', so that answers could be standardized. However, it is not known if the average patient definition accurately reflected an average patient seen by respondents, and if not, how this might have impacted the responses, but no respondents raised this as an issue during the survey.

\section{Summary}

This European survey of primary and secondary care physicians supports previous findings from the DUAL clinical trial program and real-world observational studies. These previous findings based on clinical data also suggested that IDegLira is effective and an attractive alternative to basal-bolus therapy for patients with concerns about multiple injections, hypoglycemia and/or weight gain. In addition, there were no major differences between the use of IDegLira in terms of patient profiles, therapeutic outcomes and satisfaction reported by physicians from primary and secondary care. Therefore, this suggests that IDegLira is an intensification therapy that could be initiated by both PCPs and specialists. Importantly, respondents were satisfied with IDegLira, more so than with basal-bolus regimens.

Acknowledgements The authors would like to thank the physicians for their participation, Brian Larsen Thorsted, Anne Kaas and Sarah Eggert (Novo Nordisk) for their review and input to the manuscript, and Jens Harald Kongsø (Novo Nordisk at the time of survey development) for his input into the survey development.

Contributors AmB and MD contributed to the design, analysis and manuscript writing. AnB contributed to the conduct/data collection, analysis and manuscript writing. $\mathrm{RD}$ and $\mathrm{B}-\mathrm{OT}$ contributed to the analysis and manuscript writing. The authors take full responsibility for the final content and the decision to submit the article for publication.

Funding The survey and the manuscript were sponsored by Novo Nordisk. The survey was conducted by QuintilesIMS, and medical writing assistance and submission support were provided by Victoria Atess and Germanicus HansaWilkinson of Watermeadow Medical, an Ashfield company, part of UDG Healthcare, funded by Novo Nordisk.

Competing interests $\mathrm{RD}$ has received speaker fees, fees for advisory service and support to attend educational meetings from Novo Nordisk, Sanofi, Takeda, AstraZeneca, Eli Lilly, Boehringer Ingelheim, and Merck, Sharp \& Dohme. AnB has no conflicts of interest to declare. AmB and MD are employees of Novo Nordisk. B-OT has received speaker fees, fees for advisory service and support to attend educational meetings from Novo Nordisk, Sanofi, AstraZeneca, Eli Lilly, Boehringer Ingelheim, and Merck, Sharp \& Dohme.

Patient consent Not required.

Provenance and peer review Not commissioned; externally peer reviewed. Data sharing statement This material has not been published previously and is not under consideration for publication elsewhere.

Open access This is an Open Access article distributed in accordance with the Creative Commons Attribution Non Commercial (CC BY-NC 4.0) license, which permits others to distribute, remix, adapt, build upon this work non-commercially, and license their derivative works on different terms, provided the original work is properly cited and the use is non-commercial. See: http://creativecommons.org/ licenses/by-nc/4.0/

C Article author(s) (or their employer(s) unless otherwise stated in the text of the article) 2018. All rights reserved. No commercial use is permitted unless otherwise expressly granted.

\section{REFERENCES}

1. Novo Nordisk. Xultophy® Presribing Information (PI). 2016. https://www.accessdata.fda.gov/drugsatfda_docs/label/2016/ 208583s000lbl.pdf (accessed Jul 2017).

2. Novo Nordisk. Xultophy® Summary of Product Characteristics. 2017. https://www.medicines.org.uk/emc/medicine/29493 (accessed Jul 2017).

3. Greig SL, Scott LJ. Insulin degludec/liraglutide: A review in type 2 diabetes. Drugs 2015;75:1523-34.

4. Vedtofte L, Knop FK, Vilsbøll T. Efficacy and safety of fixed-ratio combination of insulin degludec and liraglutide (IDegLira) for the treatment of type 2 diabetes. Expert Opin Drug Saf 2017;16:387-96.

5. Cohen ND, Audehm R, Pretorius E, et al. The rationale for combining GLP-1 receptor agonists with basal insulin. Med J Aust 2013;199:246-9.

6. Khunti K, Millar-Jones D. Clinical inertia to insulin initiation and intensification in the UK: A focused literature review. Prim Care Diabetes 2017;11:3-12.

7. Khunti K, Wolden ML, Thorsted BL, et al. Clinical inertia in people with type 2 diabetes: a retrospective cohort study of more than 80,000 people. Diabetes Care 2013;36:3411-7. 
8. Khunti K, Nikolajsen A, Thorsted BL, et al. Clinical inertia with regard to intensifying therapy in people with type 2 diabetes treated with basal insulin. Diabetes Obes Metab 2016;18:401-9.

9. Inzucchi SE, Bergenstal RM, Buse JB, et al. Management of hyperglycemia in type 2 diabetes: a patient-centered approach: position statement of the American Diabetes Association (ADA) and the European Association for the Study of Diabetes (EASD). Diabetes Care 2012;35:1364-79.

10. American Diabetes Association. Standards of Medical Care in Diabetes-2017 Abridged for Primary Care Providers. Clin Diabetes 2017;35:5-26.

11. Bellido V, Suarez L, Rodriguez MG, et al. Comparison of basal-bolus and premixed insulin regimens in hospitalized patients with type 2 diabetes. Diabetes Care 2015;38:2211-6.

12. Jehle PM, Micheler C, Jehle DR, et al. Inadequate suspension of neutral protamine Hagendorn (NPH) insulin in pens. Lancet 1999;354:1604-7.

13. Buse JB, Vilsbøll T, Thurman J, et al. Contribution of liraglutide in the fixed-ratio combination of insulin degludec and liraglutide (IDegLira). Diabetes Care 2014;37:2926-33.

14. Gough SC, Bode B, Woo V, et al. NN9068-3697 (DUAL-I) trial investigators. Efficacy and safety of a fixed-ratio combination of insulin degludec and liraglutide (IDegLira) compared with its components given alone: results of a phase 3, open-label, randomised, 26-week, treat-to-target trial in insulin-naive patients with type 2 diabetes. Lancet Diabetes Endocrinol 2014;2:885-93.

15. Harris SB, Kocsis G, Prager R, et al. Safety and efficacy of IDegLira titrated once weekly versus twice weekly in patients with type 2 diabetes uncontrolled on oral antidiabetic drugs: DUAL VI randomized clinical trial. Diabetes Obes Metab 2017;19:858-65.

16. Lingvay I, Pérez Manghi F, García-Hernández P, et al. Effect of insulin glargine up-titration vs insulin degludec/liraglutide on glycated hemoglobin levels in patients with uncontrolled type 2 diabetes: The DUAL V Randomized Clinical Trial. JAMA 2016;315:898-907.

17. Linjawi S, Bode BW, Chaykin LB, et al. The Efficacy of IDegLira (Insulin Degludec/Liraglutide Combination) in adults with type 2 diabetes inadequately controlled with a GLP-1 receptor agonist and oral therapy: DUAL III randomized clinical trial. Diabetes Ther 2017;8:101-14.

18. Rodbard HW, Bode BW, Harris SB, et al. Safety and efficacy of insulin degludec/liraglutide (IDegLira) added to sulphonylurea alone or to sulphonylurea and metformin in insulin-naïve people with Type 2 diabetes: the DUAL IV trial. Diabetic Medicine 2017;34:189-96.

19. Billings LK, Doshi A, Gouet D, et al. Efficacy and Safety of IDegLira versus basal-bolus insulin therapy in patients with type 2 diabetes uncontrolled on metformin and basal insulin: The DUAL VII randomized clinical trial. Diabetes Care 2018;41:1009-16.

20. Wyatt K, Hall L. No or Aye to Xultophy? Experience of fixed combination insulin Degludec and Liraglutide in Wishaw General Hospital. Diabet Med 2017;34(Suppl.s1):189-94. Abstract P511.
21. Sofra D. Glycemic control in a real-life setting in patients with type 2 diabetes treated with ideglira at a single swiss center. Diabetes Ther 2017;8:377-84.

22. Price $\mathrm{H}$, Blüher $\mathrm{M}$, Prager $\mathrm{R}$, et al. Use and effectiveness of a fixed-ratio combination of insulin degludec/liraglutide (IDegLira) in a real-world population with type 2 diabetes: Results from a European, multicentre, retrospective chart review study. Diabetes Obes Metab 2018;20:954-62

23. Hunt B, Mocarski M, Valentine WJ, et al. Evaluation of the short-term cost-effectiveness of IDegLira versus continued up-titration of insulin glargine u100 in patients with type 2 diabetes in the USA. Adv Ther 2017;34:954-65.

24. Russell-Jones D, Pouwer F, Khunti K. Identification of barriers to insulin therapy and approaches to overcoming them. Diabetes Obes Metab 2018;20:488-96.

25. Calvert MJ, McManus RJ, Freemantle N. Management of type 2 diabetes with multiple oral hypoglycaemic agents or insulin in primary care: retrospective cohort study. $\mathrm{Br} J$ Gen Pract 2007;57:455-60.

26. de Pablos-Velasco P, Parhofer KG, Bradley C, et al. Current level of glycaemic control and its associated factors in patients with type 2 diabetes across Europe: data from the PANORAMA study. Clin Endocrinol 2014;80:47-56.

27. Blak BT, Smith HT, Hards M, et al. A retrospective database study of insulin initiation in patients with Type 2 diabetes in UK primary care. Diabet Med 2012;29:e191-e198.

28. National Institute for Health and Care Excellence. Type 2 diabetes in adults: management (NG28). NICE guideline 2015.

29. Shah BR, Hux JE, Laupacis A, et al. Clinical inertia in response to inadequate glycemic control: do specialists differ from primary care physicians? Diabetes Care 2005;28:600-6.

30. Kunt T, Snoek FJ. Barriers to insulin initiation and intensification and how to overcome them. Int J Clin Pract Suppl 2009(164):6-10.

31. Levin PA, Wei W, Zhou S, et al. Outcomes and treatment patterns of adding a third agent to 2 OADs in patients with type 2 diabetes. $J$ Manag Care Spec Pharm 2014;20:501-12.

32. Marso SP, Daniels GH, Brown-Frandsen K, et al. Liraglutide and Cardiovascular Outcomes in Type 2 Diabetes. $N$ Engl $J$ Med 2016;375:311-22.

33. Patrick AR, Fischer MA, Choudhry NK, et al. Trends in insulin initiation and treatment intensification among patients with type 2 diabetes. J Gen Intern Med 2014;29:320-7.

34. Anderten H, Dippel FW, Kostev K. Early discontinuation and related treatment costs after initiation of Basal insulin in type 2 diabetes patients: a German primary care database analysis. J Diabetes Sci Technol 2015;9:644-50.

35. Ascher-Svanum H, Lage MJ, Perez-Nieves M, et al. Early discontinuation and restart of insulin in the treatment of type 2 diabetes mellitus. Diabetes Ther 2014;5:225-42.

36. Wei W, Pan C, Xie L, et al. Real-world insulin treatment persistence among patients with type 2 diabetes. Endocr Pract 2014;20:52-61. 


\section{Correction: Physicians' real-world experience with IDegLira: results of a European survey}

Drummond R, Baru A, Dutkiewicz M, et al. Physicians' real-world experience with IDegLira: results of a European survey. BMJ Open Diabetes Research and Care 2018;6:e000531. doi: 10.1136/bmjdrc-2018-000531

The authors traced some formatting errors in figures 2 and 3 . The correct versions are now available below:

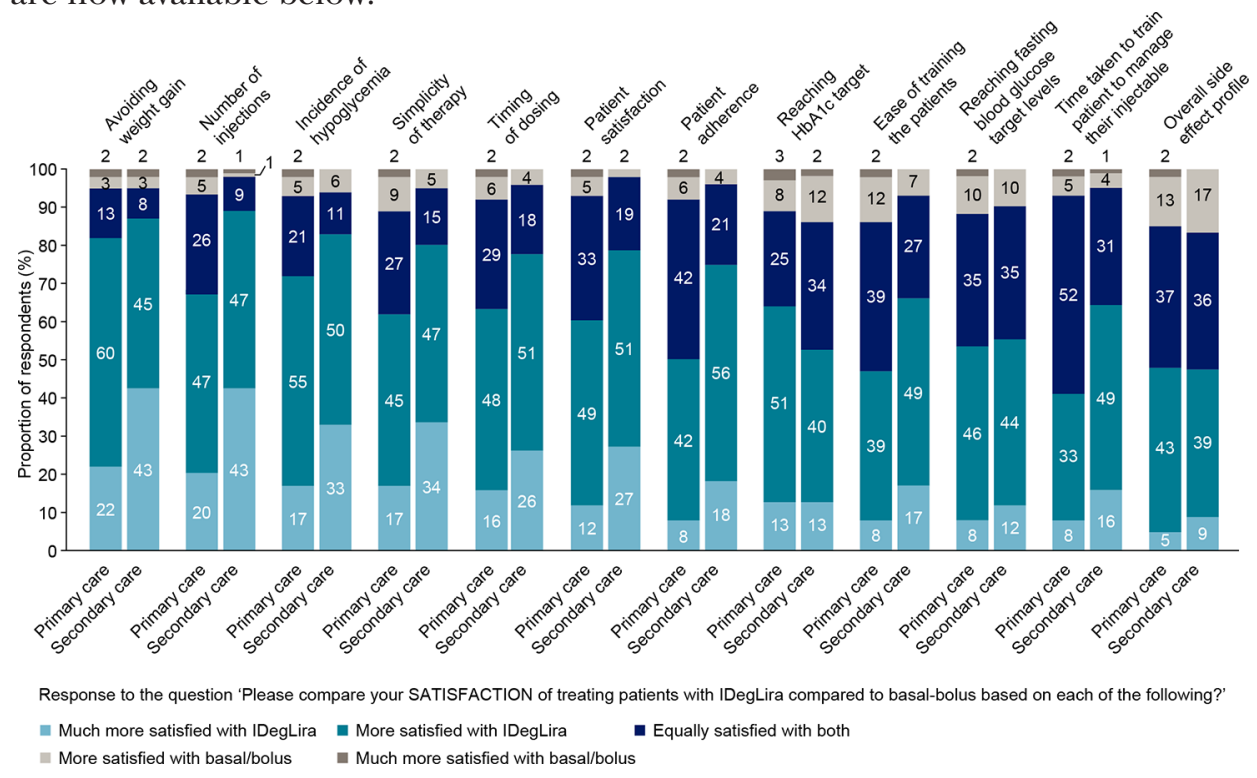

Figure 2 Satisfaction of respondents with IDegLira compared with basal-bolus. HbA1c, glycated hemoglobin; IDegLira, insulin degludec/liraglutide. 


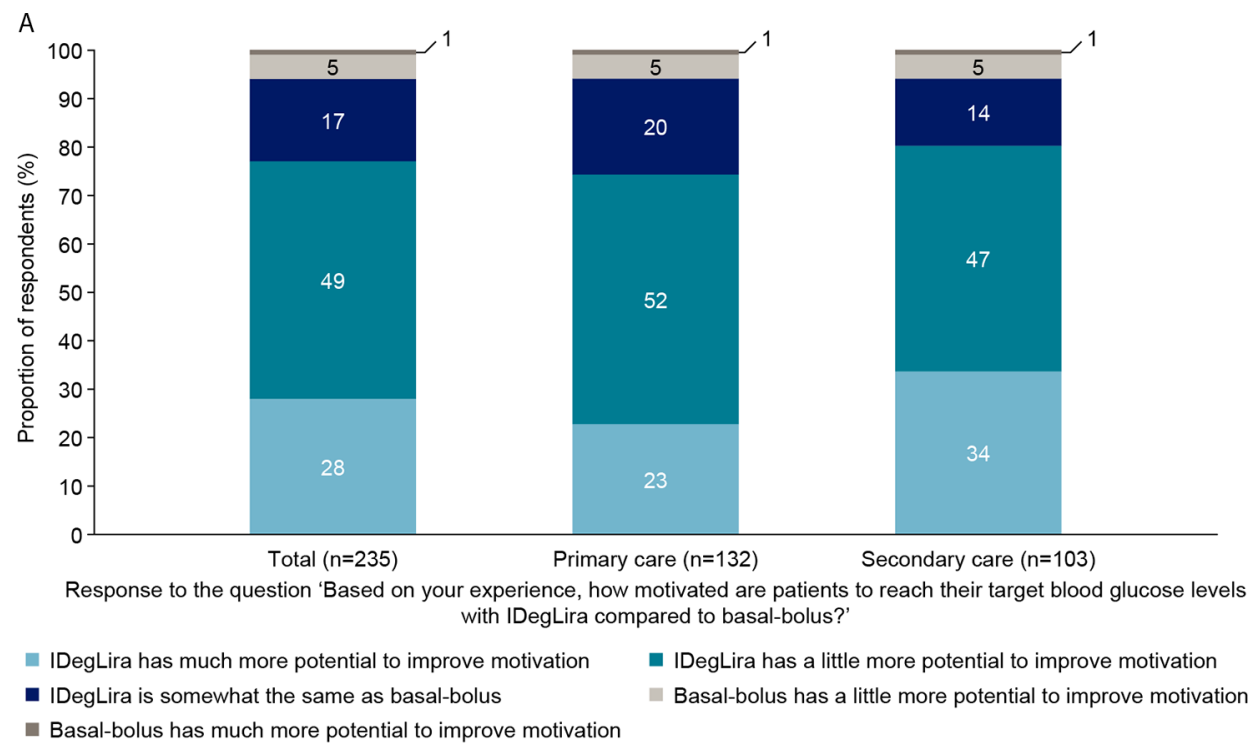

$\begin{array}{ccc}\text { Concern of patients } & \begin{array}{c}\text { Concern of patients } \\ \text { having hypoglycemia }\end{array} & \begin{array}{c}\text { Concern of patients struggling with } \\ \text { nausea and other } \mathrm{Gl} \text { effects }\end{array}\end{array}$

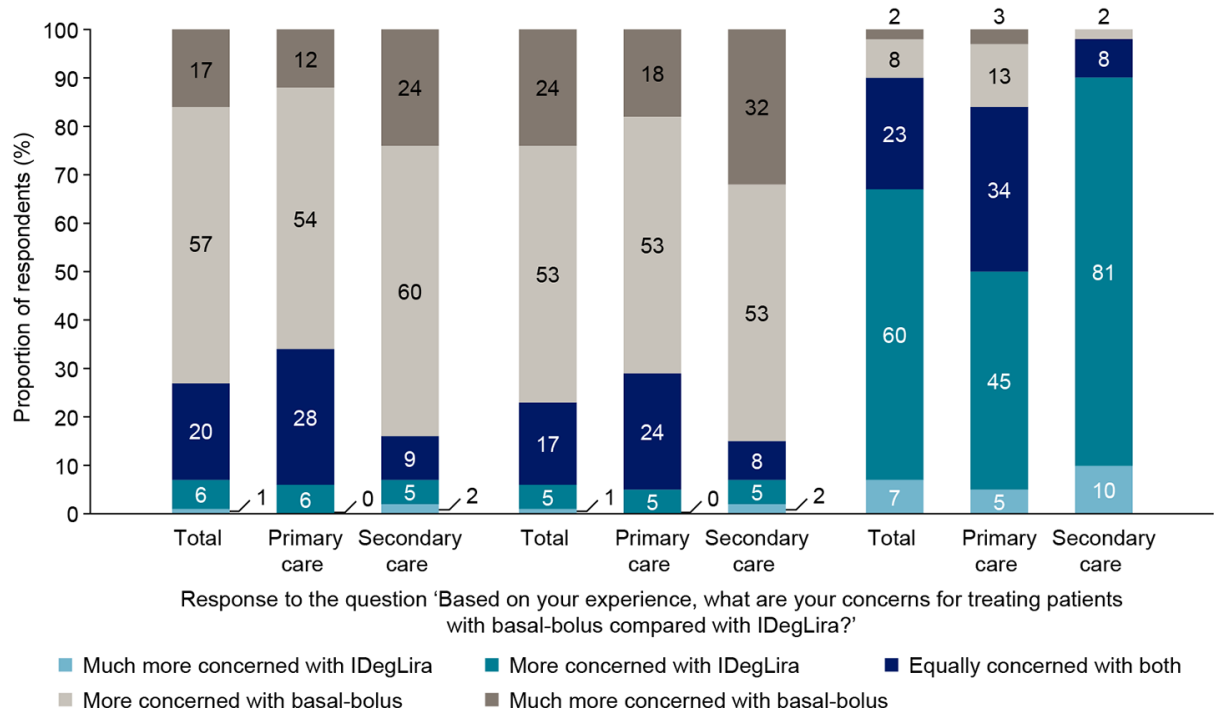

Figure 3 Respondents' perceptions on (A) the potential of IDegLira compared with basal-bolus therapy to improve patient motivation to reach their target blood glucose levels; and (B) concerns with IDegLira compared with basal-bolus therapy. GI, gastrointestinal; IDegLira, insulin degludec/liraglutide.

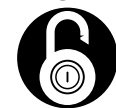

\section{OPEN ACCESS}

Open access This is an Open Access article distributed in accordance with the Creative Commons Attribution Non Commercial (CC BY-NC 4.0) license, which permits others to distribute, remix, adapt, build upon this work non-commercially, and license their derivative works on different terms, provided the original work is properly cited and the use is non-commercial. See: http://creativecommons.org/licenses/by-nc/4.0/

(C) Article author(s) (or their employer(s) unless otherwise stated in the text of the article) 2018. All rights reserved. No commercial use is permitted unless otherwise expressly granted.

BMJ Open Diab Res Care 2018;6:e00531corr1. doi:10.1136/bmjdrc-2018-000531corr1

D Check for updates 